\title{
FORMAÇÃO E INSERÇÃO PROFISSIONAL DE EGRESSOS DE PEDAGOGIA: ESTUDO DE CASO EM UMA IES CONFESSIONAL FLUMINENSE
}

Formation and professional insertion of pedagogy egresses: case study in a fluminense confessional institution

Formación e inserción profesional de egresos de pedagogía: estudio de caso en una institución confesional fluminense

Maria de Fátima Pimenta*

Marcelo Mocarzel**

Jardelino Menegat***

https://doi.org/10.38117/2675-181X.formov2021.v3i1n5.358-383.

\section{Resumo}

Este artigo caracteriza-se como um estudo de caso sobre o curso de Pedagogia de uma instituição de ensino superior confessional, localizada no estado do Rio de Janeiro. Buscou-se analisar como se deu a inserção profissional e a formação continuada dos egressos, estabelecendo relações com a visão dos mesmos acerca da formação inicial. A unidade de análise contou com 43 egressos, no espaço temporal entre os anos de 20122016, que responderam aos questionários. Constatou-se que a esmagadora maioria dos respondentes obteve progressos formativos e profissionais a partir da graduação, reconhecendo a importância da formação inicial em suas vidas.

Palavras-chave: Egressos; Curso de Pedagogia; Formação; Desenvolvimento profissional.

\begin{abstract}
This article is characterized as a Case Study on the Pedagogy Course of a confessional higher education institution, located in the state of Rio de Janeiro. We sought to analyze how the graduates' professional insertion and continued training took place, establishing relationships with their view of the initial training. The analysis unit had 43 graduates, in
\end{abstract}


Formação e Inserção profissional de egressos de Pedagogia: Estudo de caso em uma IES Confessional fluminnese

the time span between the years 2012-2016, who answered the questionnaires. It was found that the overwhelming majority of respondents achieved training and professional progress after graduation, recognizing the importance of initial training in their lives.

Keywords: Graduates; Pedagogy Course; Formation; Professional development.

\section{Resumen}

Este artículo se caracteriza como un estudio de caso sobre el curso de pedagogía de una institución de educación superior confesional, ubicada en el estado de Rio de Janeiro. Intentamos analizar cómo se llevó a cabo la inserción profesional y la educación continua de los graduados, estableciendo relaciones con su visión de la formación inicial. La unidad de análisis contó con 43 graduados, en el período comprendido entre los años 2012-2016, que respondieron los cuestionarios. Se descubrió que la gran mayoría de los encuestados lograron capacitación y progreso profesional después de la graduación, reconociendo la importancia de la capacitación inicial en sus vidas.

Palabras clave: Graduados; Curso de pedagogía; Formación; Desarrollo profesional.

\section{Introdução}

A reflexão sobre a formação do licenciado em Pedagogia está revestida de importância no contexto do ideário do direito à educação, considerando-se que a melhoria da qualidade da educação está relacionada à qualidade da formação dos professores (inicial e continuada); às condições de trabalho; à motivação desses profissionais no exercício da docência; ao reconhecimento profissional pela comunidade escolar em que atua e pela própria sociedade, como um todo; à sua valorização expressa através de remuneração digna; à corresponsabilização da família no processo educativo, dentre outros. Gadotti (2000, p. 9) nos inspira a refletir sobre o que é ser professor na contemporaneidade, que é "viver intensamente o seu tempo, conviver; é ter consciência e sensibilidade. [...] Os educadores, numa visão emancipadora, não só transformam a informação em conhecimento e em consciência crítica, mas também formam pessoas".

Nesse sentido, nossa proposta de estudo foi analisar as trajetórias dos egressos de um curso de Pedagogia, em relação às contribuições para o desenvolvimento pessoal e profissional. Onde se encontram esses egressos? Estão prosseguindo nos estudos de pós-graduação? Estão trabalhando na área educacional? Essas e outras 
questões motivaram as análises. A unidade de análise contou com 43 egressos respondentes, no espaço temporal entre os anos de 2012-2016.

A LDB - Lei de Diretrizes e Bases da Educação Nacional (BRASIL, 1996) aponta claramente que a Educação tem por finalidade o pleno desenvolvimento do educando, seu preparo para o exercício da cidadania e sua qualificação para o trabalho (art. $2^{\circ}$ ). O artigo 43, II, da mesma LDB, estabelece como finalidade da Educação Superior a formação de graduados nas diferentes áreas de conhecimento, aptos para a inserção em setores profissionais, para a participação no desenvolvimento da sociedade brasileira e para a colaboração na sua formação contínua. Tal é a preocupação da LDB com as aptidões dos diplomados para a inserção profissional, que a Resolução CNE/CP n ${ }^{\circ} 1$, de 15 de maio de 2006 (BRASIL, 2006), em seu art. $5^{\circ}$, reúne 16 incisos sobre as capacidades que os egressos deverão adquirir.

O método de pesquisa, Estudo de Caso (EC), é abordado por autores como André (1984), Yin (2015), entre outros. Na educação, o EC como forma de investigação é algo relativamente recente. Segundo André (1984), seu principal marco é provavelmente uma Conferência Internacional realizada em dezembro de 1975, em Cambridge, Inglaterra, sob o tema: Métodos de Estudo de Caso em Pesquisa e Avaliação Educacional, quando foram levantadas e debatidas várias questões relacionadas ao uso dessa abordagem no campo da educação. Nessa Conferência, o EC foi definido como uma forma particular de estudo que sempre envolve uma instância em ação.

André (1984, p. 54) registra que a característica que distingue melhor o EC é a ênfase na singularidade, no particular, implicando "que o objeto de estudo seja examinado como único, constituindo-se uma representação singular da realidade, que é multidimensional e historicamente situada". A sua utilização está implícita na necessidade de um contato estreito e prolongado do pesquisador com a situação ou objeto pesquisado. $\mathrm{O}$ fato relevante é que o EC não privilegia apenas um estilo de apresentação, mas procura formas que evocam os processos de julgamento que as pessoas usualmente empregam para compreender a vida e as ações sociais que as cercam.

Dessa forma, para Yin (2015, p. 32), “Um estudo de caso é uma investigação empírica que investiga um fenômeno contemporâneo dentro de seu contexto da vida real, especialmente quando os limites entre o fenômeno e o contexto não estão claramente definidos". Na explicação de Yin, (2015), a opção pelo EC pode se dar pelo desejo de entender um fenômeno do mundo real, assumindo que esse 
Formação e Inserção profissional de egressos de Pedagogia: Estudo de caso em uma IES Confessional fluminnese

entendimento presumivelmente abranja consideráveis condições contextuais apropriadas ao caso que se tem.

O autor esclarece que nos ECs o fenômeno e o contexto não estão visivelmente distinguíveis nas situações do mundo real, favorecendo que outras características sejam relevantes como as definidas em um EC, descritas a seguir: i) enfrenta a situação tecnicamente diferenciada em que existirão muito mais variáveis de interesse do que pontos de dados; ii) como resultado, conta com múltiplas fontes de evidência, com os dados precisando convergir de maneira triangular; iii) como outro resultado, beneficia-se do desenvolvimento anterior das proposições teóricas para orientar a coleta e a análise de dados.

Para situar a discussão e contextualizar a pesquisa, iniciaremos com um breve histórico do curso de Pedagogia no Brasil, a partir de alguns marcos políticos.

\section{Histórico e marcos do curso de Pedagogia no Brasil}

A trajetória profissional dos pedagogos está imersa em um debate até hoje não concluído que remonta os anos 1980. Desde então, a Associação Nacional pela Formação dos Profissionais da Educação (ANFOPE) tem direcionado sua luta pela defesa de políticas de formação que assegurem o reconhecimento social do Magistério, bem como seu exercício profissional. Nesse sentido, a ANFOPE sempre foi contrária à concepção de pedagogo como especialista, defendendo, desde o I Encontro Nacional de Belo Horizonte, em 1983, a formação na docência, com uma base comum nacional para os cursos de Pedagogia e demais licenciaturas. Portanto, para a ANFOPE, a docência constitui a identidade do profissional.

O período inicial (1939-1972), de nascimento e definição, preocupa-se com as regulamentações e os destinos abertos para o profissionalismo de seus egressos; em suma, buscava-se, nessa época, uma identidade para o Curso, em meio a discussões, desconfianças, apreensões e dúvidas acerca de conteúdos congruentes para a sua institucionalização e permanência. Nesse ambiente de imprecisões, uma definição se assenta: a sala de aula era o espaço de atuação do licenciado; por seu turno, funções técnicas no Ministério da Educação e funções de inspeção e similares burocráticos eram da alçada do bacharel (SILVA, 2003).

Por obra do Conselheiro Valnir Chagas (que desde a criação do Curso já se comprometia em tomadas de decisões), o segundo período a partir de 1973 é marcado 
pelo desdobramento do Curso em alternativas distintas de habilitações, a chamada licenciatura das áreas pedagógicas (SILVA, 2003). Caracterizado pela autora, de acordo com as propostas, o terceiro período (1979-1998) é também marcado por discussões acirradas em defesa do Curso, por docentes e universitários que formam um movimento de resistência às reformas impostas num momento inicial de regime militar ditatorial e, depois (a partir de 1980) de propostas de redemocratização. O que se mantém ativo ainda são os encontros e seminários pelo país em prol da construção do perfil identitário do pedagogo e do próprio Curso (SILVA, 2003).

Silva (2003) denomina o quarto período, que iniciou em 1999, como período dos decretos. Também de inflamadas discussões decorrentes do Decreto 3.276/1999, do Presidente da República, determinando que cabia aos cursos normais superiores a formação de docentes para séries iniciais. Diante da resistência dos envolvidos, o Decreto 3.554/2000 substitui o anterior, que determina o termo "exclusivamente" por "preferencialmente", de modo que o curso de Pedagogia consegue recuperar a sua função de licenciatura, ainda que secundarizada. Surge, em fevereiro de 2001, uma Comissão de Especialistas de Ensino de Pedagogia que consegue desdobrar a formação do pedagogo em duas vertentes, mas de forma que, nas duas, a docência é estabelecida como fundamento da organização curricular e, por conseguinte, de sua identidade (SILVA, 2003).

Saviani (2012), a partir de sua pesquisa "O espaço acadêmico da Pedagogia no Brasil: perspectiva histórica e teórica", deu origem à obra "A pedagogia no Brasil: história e teoria". Nesta, Saviani destaca as diferentes formas pelas quais a Pedagogia foi definida ao longo da história, buscando manter uma relação dialética entre a produção de uma prática de ensino e a de um modelo teórico de interpretação da aprendizagem. Para o autor, foi a partir do século XIX que o termo pedagogia tendeu a se generalizar para mostrar a conexão entre a elaboração consciente da ideia de educação e o fazer consciente do processo educativo, fenômeno este sentido de forma mais acentuada nas línguas germânicas e latinas do que nas línguas anglo-saxônicas, e estreitamente vinculado ao problema da formação de professores.

Em decorrência disso, Saviani (2012) registra o predomínio nas universidades e demais instituições de ensino superior, incumbidas de formar o professor para o nível secundário, do primeiro modelo dos conteúdos culturais-cognitivos, que compreendeu a cultura geral e o domínio específico dos conteúdos da área de conhecimento relacionada à disciplina ministrada. O segundo modelo, referente ao pedagógico-didático, voltou-se para a formação dos professores primários, nas Escolas Normais. 
Formação e Inserção profissional de egressos de Pedagogia: Estudo de caso em uma IES Confessional fluminnese

Após a aprovação do Estatuto das Universidades, de 1931, da lavra do então ministro da Educação e Saúde Pública, Francisco Campos, surgiram os cursos de Pedagogia na Faculdade de Filosofia, Ciências e Letras da Universidade de São Paulo e na Universidade do Distrito Federal (UDF), que, criada em 1935, foi extinta em 1939, com a fundação da Universidade do Brasil, atual Universidade Federal do Rio de Janeiro (UFRJ) e da sua Faculdade Nacional de Filosofia, Ciências e Letras (GALVÃO, 2017).

A organização do campo educacional implicava a profissionalização da atividade dos educadores e professores, e esta, por sua vez, demandava uma formação específica, o que teve início no século XIX com as tentativas intermitentes de criação de Escolas Normais para a formação de professores primários, as quais vieram a se consolidar no século XX, voltadas para o ensino primário e secundário, ocasionando a exigência de se abrir espaço para os estudos pedagógicos em nível superior (SAVIANI, 2009).

A partir da década de 1930, a Pedagogia ocupou um espaço permanente na estrutura do Ensino Superior que, por sua vez, limitou-se à oferta de disciplinas destinadas à formação de determinados profissionais da educação, o que levou Saviani a concluir que esse tipo de estudo oferecido não possuía natureza investigativa. Por isso, foi considerado pouco consistente de fundamentação teórico-científica. Nesse contexto, do surgimento do curso de Pedagogia, em fins dos anos de 1930, desenvolveu-se um esforço intencional no sentido de constituir a Pedagogia, ao mesmo tempo como uma profissão de base científica e como uma área de investigação específica com objeto e métodos próprios. Ainda, para Saviani (2009, p. 154), do ponto de vista teórico, há de se evidenciar nesse processo dois momentos distintos, representados pela emergência e predominância da concepção pedagógica renovadora, que atingiu o apogeu e entrou em declínio na década de 1960, e a que se identifica pelo advento da concepção pedagógica produtivista.

A abordagem de Saviani (2009) compreende o período do aparecimento da Pedagogia Nova (1932-1969) e o predomínio da Pedagogia Produtivista (1969-2001), com concepções pedagógicas contra-hegemônicas, perpassando e coexistindo com essas duas, ressaltando os dilemas e as polêmicas no campo pedagógico, de forma a argumentar sobre que tipo de profissional se deve formar nos cursos de Pedagogia, com vista ao enfrentamento da nova realidade educacional vivida no país e no mundo, e ainda, que formato deve ter o curso de Pedagogia para formar esse profissional do século XXI. 
Os cursos de Pedagogia, respaldados por fundamentos legais, foram organizados no Brasil a partir de 1939 pelo Decreto-Lei $\mathrm{n}^{\circ} 1.190$, de 4 de abril de 1939, que "Dá organização à Faculdade Nacional de Filosofia". Dentre suas finalidades deverá "preparar o candidato ao magistério do ensino secundário e normal" (BRASIL, 1939, p. 1). Conforme Silva (2003), desde a gênese, o curso foi motivo de polêmica, por não haver mercado profissional para engajamento dos pedagogos, dada a inexistência de campo de atuação, em razão de uma formação inadequada resultante da tensão entre o teor generalista das disciplinas e o exercício de funções de natureza técnica.

Trinta anos depois, de autoria de Valnir Chagas, o Parecer CFE $\mathrm{n}^{\circ}$. 252, de 11 de abril de 1969 (BRASIL, 1969), direcionou a formação do pedagogo para a Licenciatura, excluindo o bacharelado. Estabeleceu-se, pois, a primeira regulamentação específica para o curso de Pedagogia, fixando currículo mínimo e duração desse Curso.

A partir da década de 1970, de acordo com Silva (2011), novas formulações se fizeram presentes por conta do movimento de revisão dos cursos de Pedagogia e outras licenciaturas, denominando-se de fundamentos paralegais, por estarem de acordo com os preceitos legais e se caracterizarem como os verdadeiros orientadores das reformulações na maior parte dos cursos.

A Lei 5.692, de 11 de agosto de 1971 (BRASIL, 1971), fixou diretrizes e bases para o ensino de $1^{\circ}$ e $2^{\circ}$ graus. Mesmo sem incidir diretamente sobre o ensino superior, trouxe consequências para os cursos de Pedagogia. Ao estabelecer as exigências de formação do corpo docente, o artigo 30 determinava o curso de Licenciatura Plena em nível superior como formador de professores para atuarem em todo o ensino de $1^{\circ} \mathrm{e}$ $2^{\circ}$ graus, mesmo que o graduado não tivesse o Curso Normal (específico para atuarem nas séries iniciais do $1^{\circ}$ grau), considerando o fato de que quem pode mais pode menos e desconhecendo, de certa forma, as especificidades dos anos iniciais da escolarização.

Ainda nos anos 1970, o Conselheiro Valnir Chagas caracteriza o pedagogo como um dos especialistas em educação, sendo aquele "que se aprofunda na teoria, nos fundamentos ou metodologia da educação" (SILVA, 2003, p. 60). Com a presumível extinção do curso de Pedagogia (motivo de acirradas polêmicas da comunidade universitária envolvida em seminários e debates), tornaram-se dificultadas as determinações do Conselho Federal de Educação, e daí emergindo discussões na esfera nacional. 
Formação e Inserção profissional de egressos de Pedagogia: Estudo de caso em uma IES Confessional fluminnese

O que se destaca na década de 1980 é a preocupação com a formação do educador, a partir de concepções avançadas, superadoras de dicotomias (professores $\mathrm{X}$ especialistas; pedagogia $\mathrm{X}$ licenciaturas; especialistas $\mathrm{X}$ generalistas) e avessas ao tecnicismo que a antecedera. No contexto de acaloradas discussões - em fóruns, seminários, encontros, muitos desses movimentos apoiados pelo Comitê Nacional e pela Comissão Nacional pela Reformulação dos Cursos de Formação do Educador (Conarcfe), e na sequência e até a atualidade pela Anfope -, consoante Freitas (2002, p. 140), "as reformulações curriculares, particularmente no âmbito da formação de professores de educação infantil e séries iniciais do Ensino Fundamental, no interior dos cursos de pedagogia, cresceram e prosperaram com base nas concepções mais progressistas e avançadas". Observa-se, porém, que os anos 1980 não foram assinalados por dispositivos legais federais, mas essa década

[...] representou, para os educadores, o marco da reação ao pensamento tecnicista das décadas de 1960 e 1970, os anos 90, contraditoriamente, foram marcados também pela centralidade no conteúdo da escola (habilidades e competências escolares), fazendo com que fossem perdidas dimensões importantes que estiveram presentes no debate dos anos 80 (FREITAS, 2002, p. 141).

Tanuri (2000) evidencia que o debate sobre a formação de professores para os anos iniciais revigoraram a partir dos anos 1980, quando da instalação dos Centros Específicos de Formação e Aperfeiçoamento do Magistério (Cefam), e as iniciativas de reestruturação curricular das escolas normais e dos cursos de Pedagogia, com as experiências de novos cursos de formação em nível superior e, ainda, com a produção acadêmica intensa sobre o assunto, em especial com a produção crítica de autores portugueses e espanhóis sobre a tradição acadêmica de formação docente. Essas discussões atingiram maior grau com a aprovação da nova LDB, Lei 9.394/96, que, superando a questão, no que diz respeito ao nível de formação (médio ou superior), elevou a formação do professor das séries iniciais no nível superior, estabelecendo que ela se daria em universidades e em institutos superiores de educação, nas licenciaturas e em cursos normais superiores. A análise de Tanuri (2000) retrata, então, essa movimentação no cenário educacional: o momento em que a escola normal passa a nível superior, em que se discute o lócus de formação de professores (Universidades versus Institutos Superiores de Educação) e em que se questiona o projeto pedagógico e os saberes inerentes a essa formação, pela mesma autora considerado como propício ao resgate e à construção da informação histórica.

Formação adequada dos professores deveria ser um pilar da qualidade e do direito à educação. Porém, no Brasil, vivenciamos a constante desvalorização da 
formação, com rupturas e retrocessos, indicando um projeto que descaracteriza o sentido de emancipação que é assegurado nos principais marcos legais nacionais, como a Constituição e a LDB.

O ideário do direito à educação, como um direito a ser assegurado ao lado de um conjunto de outros direitos fundamentais à dignidade da pessoa humana, encontra-se presente em dispositivos legais, tanto no âmbito nacional quanto internacional. No âmbito internacional, destacamos alguns documentos, tais como: a Declaração Mundial sobre Educação para Todos (UNESCO, 1990); o Marco de Ação de Dakar-Educação para Todos: assumindo nossos compromissos coletivos (UNESCO, 2001); A Educação que queremos para a geração dos bicentenários: as metas educativas 2021, e a Educação 2030 - Declaração e Marco de Ação de Incheon: Rumo a uma educação de qualidade inclusiva e equitativa e à educação ao longo da vida para todos (UNESCO, 2015a).

Tais documentos possuem como cerne o proposto pela Declaração Universal dos Direitos Humanos (ONU, 1948), um dos principais pilares teóricos, jurídicos, políticos e educacionais da criação de um Sistema de Proteção Internacional de Direitos Humanos e do movimento contemporâneo em prol da defesa desses direitos.

As Metas Educativas 2021 se constituem em um documento elaborado, a partir do acordo firmado na XVIII Conferência Ibero-americana de Educação, celebrada em 19 de maio de 2008, na cidade de El Salvador. O objetivo dessa Conferência foi iniciar a construção de um projeto, tendo como cerne o estabelecimento e o acordo, no ano de 2010, de um conjunto de "metas e indicadores que impulsionem a educação de cada um dos países" situados no contexto ibero-americano (OEI, 2008), tendo em vista

[...] conseguir ao longo da próxima década uma educação que responda satisfatoriamente às demandas sociais inadiáveis: conseguir que mais alunos estudem, durante mais tempo, com uma oferta de qualidade reconhecida, equitativa e inclusiva, e na qual participe a grande maioria das instituições e setores da sociedade. Existe, pois, a certeza de que a educação é a estratégia fundamental para avançar na coesão e na inclusão social (OEI, 2008, p. 3).

Uma das dimensões essenciais a serem consideradas, dentre outras, para que tal objetivo se consolide é a formação docente. De acordo com o referido documento:

Conseguir que o docente esteja preparado e motivado para exercer com acerto sua tarefa profissional é, sem dúvida, o fator que mais influi na melhoria da qualidade de ensino. Para isso, é necessário cuidar da formação inicial e continuada dos 
Formação e Inserção profissional de egressos de Pedagogia: Estudo de caso em uma IES Confessional fluminnese

docentes, o acesso ao trabalho docente e seus primeiros anos de desempenho profissional, suas condições laborais e seu desenvolvimento profissional. É necessário, ao mesmo tempo, propor novas estratégias que ajudem o docente, entre as que cabem destaque, o apoio à criação de redes de escolas e de professores, a ampliação dos programas de inovação, avaliação e pesquisa educativa, e formulação de projetos de formação que relacionem a teoria e a prática e que orientem de forma prioritária os grupos de professores que trabalham na mesma escola (OEI, 2008, p. 76, grifo do documento).

Dessa forma, o documento estabelece em sua oitava meta "Fortalecer a Profissão Docente" (OEI, 2010, p. 56), a qual se desdobra em duas metas específicas, a meta 20: "Melhorar a formação inicial dos professores do ensino fundamental e do ensino médio" (OEI, 2010, p. 56) e a 21: "Favorecer a capacitação continuada e o desenvolvimento da carreira profissional docente" (OEI, 2010, p. 58). O documento, ao abordar a questão da formação docente, destaca que "sem a competência e a colaboração da maioria dos professores, não é possível a mudança e a melhoria da educação" (OEI, 2010, p. 58). Tal ênfase nos remete à questão do protagonismo docente, ou seja, o comprometimento que o profissional da educação necessita possuir tanto com sua formação quanto com o fazer educativo cotidiano.

No Brasil, o movimento em prol dos direitos humanos e sociais tem como um dos marcos significativos a promulgação da Constituição da República Federativa Brasileira (BRASIL, 1988), que enfatizou como princípio fundamental o valor da dignidade humana. Ao se falar em dignidade humana, pode-se afirmar que ela se constitui de uma

[...] qualidade intrínseca e distintiva de cada ser humano que o faz merecedor do mesmo respeito e consideração por parte do Estado e da comunidade, implicando, neste sentido, um complexo de direitos e deveres fundamentais que assegurem a pessoa tanto contra todo e qualquer ato de cunho degradante e desumano, como venham a lhe garantir as condições existenciais mínimas para uma vida saudável, além de propiciar e promover sua participação ativa corresponsável nos destinos da própria existência e da vida em comunhão dos demais seres humanos (SARLET, 2001, p. 60).

No Capítulo III da Constituição, Seção I, Art. 205 (BRASIL, 1988) consta que "A educação, direito de todos e dever do Estado e da família, será promovida e incentivada com a colaboração da sociedade" com vistas "ao pleno desenvolvimento da 
pessoa, seu preparo para o exercício da cidadania e sua qualificação para o trabalho", sendo a "educação básica obrigatória e gratuita dos 4 (quatro) aos 17 (dezessete) anos de idade, conforme Emenda Constitucional de 2009, assegurada inclusive sua oferta gratuita para todos os que a ela não tiveram acesso na idade própria" (BRASIL, 1988, Artigo 208, inciso I).

Houve reformas para todos os níveis de ensino, iniciadas no Governo de Fernando Henrique (1995-2002) e continuadas no de Luís Inácio Lula da Silva (20032010). Em 1996 é promulgada a LDB da Educação Nacional, no 9.394 (BRASIL, 1996). Resultante dela, foram elaboradas as DCNs, abrangendo cursos de graduação e de formação docente em nível superior, porém, não contemplando o curso de Pedagogia - o que só viria a se confirmar em maio de 2006 com a Resolução no 1/2006, pelo Conselho Nacional de Educação (CNE), após inúmeras contendas, em especial em 2005, entre pedagogos/ pesquisadores (BRASIL, 2006).

Pelo exposto sobre os dispositivos legais relativos à formação do pedagogo no Brasil, Saviani (2009) faz uma retrospectiva no tempo, argumentando que, embora a necessidade da formação docente tenha sido preconizada por Comenius, no século XVII, e o primeiro estabelecimento de ensino instituído por João Batista de La Salle, em 1684, em Reims, com o nome de Seminário dos Mestres, somente no século XIX a questão da formação de professores mereceu uma resposta institucional para o problema da instrução popular, em decorrência da Revolução Francesa, originando, dessa forma, a criação de Escolas Normais, com a finalidade de preparar professores para o ensino secundário. A questão com o preparo de professores tomou vulto após a independência, quando se pensou na organização da instrução popular.

Gatti (2010) faz inferências à formação de professores no Brasil, a partir de pesquisas publicadas nos anos 2008 e 2009 - considerando a legislação relativa a essa formação, as características socioeducacionais dos licenciados, as características dos cursos formadores de professores, os currículos e ementas de Licenciaturas em Pedagogia e outras - depreendendo, daí, o quão preocupante é o cenário dessas formações, requerendo maior atenção aos aspectos relacionados às ambiguidades das normatizações vigentes, à fragmentação da formação entre e intracurso, bem como à parte curricular específica para o trabalho docente.

Depreende-se então que, no Brasil, a formação do pedagogo é marcada por rupturas e descontinuidades, sobretudo por conta de políticas emergenciais e sem uma visão sistêmica, como se demonstra nesta seção, recorrendo-se à própria legislação pertinente à formação do pedagogo e apreciações de autores ora mencionados, 
Formação e Inserção profissional de egressos de Pedagogia: Estudo de caso em uma IES Confessional fluminnese

especialmente Silva (2003; 2011), Freitas (2002), Gatti (2010), Saviani (2009) e Tanuri (2000). As DCN de 2006, por exemplo, buscaram resolver algumas questões problemáticas, tais como o Normal Superior, mas teve sua ação limitada em alguns sentidos.

Por isso, após muito debate com o campo educacional, em 2015 foram instituídas as Diretrizes Curriculares Nacionais para a Formação Inicial e Continuada em Nível Superior de Profissionais do Magistério para a Educação Básica (BRASIL, 2015), documento específico que estabelece os parâmetros a serem observados na proposição dos cursos de formação para o exercício da docência em nível superior. De acordo com o Art. $2^{\circ}$, parágrafo $1^{\circ}$ das Diretrizes Curriculares, a docência é compreendida

[...] como ação educativa e como processo pedagógico intencional e metódico, envolvendo conhecimentos específicos, interdisciplinares e pedagógicos, conceitos, princípios e objetivos da formação que se desenvolvem na construção e apropriação dos valores éticos, linguísticos, estéticos e políticos do conhecimento inerentes à sólida formação científica e cultural do ensinar/aprender, à socialização e construção de conhecimentos e sua inovação, em diálogo constante entre diferentes visões de mundo (BRASIL, 2015).

O egresso dos cursos de formação inicial para os profissionais do Magistério para a educação básica, em nível superior, no âmbito da graduação de licenciatura,

[...] deverá possuir um repertório de informações e habilidades composto pela pluralidade de conhecimentos teóricos e práticos, resultado do projeto pedagógico e do percurso formativo vivenciado cuja consolidação virá do seu exercício profissional, fundamentado em princípios de interdisciplinaridade, contextualização, democratização, pertinência e relevância social, ética e sensibilidade afetiva e estética, de modo a lhe permitir:

I - o conhecimento da instituição educativa como organização complexa na função de promover a educação para e na cidadania;

II - a pesquisa, a análise e a aplicação dos resultados de investigações de interesse da área educacional e específica;

III - a atuação profissional no ensino, na gestão de processos educativos e na organização e gestão de instituições de educação básica. (BRASIL, 2015, Art. $7^{\circ}$ ). 
Porém, apesar do reconhecimento público quanto ao avanço que esta Resolução trouxe, esta foi revogada, em dezembro de 2019, pela Resolução 02/2019, desconsiderando todo o esforço empreendido e destacando uma nova ruptura na história da formação brasileira. Destacamos, que para o estudo de caso de que trata este texto, a Resolução 02/2015 não foi considerada como objeto analítico, uma vez que os egressos pesquisados estudaram sob a égide da Resolução CNE/CP n ${ }^{\circ}$ 1/2006 (BRASIL, 2006). Mas, destacamos a importância da Resolução de 2015, que trouxe avanços significativos e que agora estão ameaçados.

\section{Estudo de caso}

Buscar conhecer o que pensam os professores acerca de sua formação inicial pode ser uma forma de contribuir com a "[...] tomada de consciência dos diferentes elementos que fundamentam a profissão e a integração na situação de trabalho [...]". Além disso, ainda recorrendo a este autor "O início da carreira é acompanhado também de uma fase crítica, pois é a partir das certezas e dos condicionantes da experiência prática que os professores julgam sua formação universitária anterior” (TARDIF, 2018, p. 86).

Foram enviados questionários, via e-mail, a todos os que se formaram entre 2012 e 2016, em um total de 205 egressos. Cerca de $20 \%$ deles, ou 43 egressos, responderam, Desses, $6(14,0 \%)$ formaram-se em 2012; 7 (16, 2\%) em 2013; 15 (34,9\%) em 2014; 12 $(27,9 \%)$ em 2015 e $3(7 \%)$ em 2016.

Como já mencionado, o recorte temporal dos egressos, formados entre 2012 e 2016, se refere ao Curso de Pedagogia, em um currículo referente à Resolução CNE/CP $\mathrm{n}^{\circ}$ 1/2006 (BRASIL, 2006), e, portanto, ainda não modificado pelas diretrizes curriculares para as licenciaturas (Res. 02/2015), vigentes até a homologação das Res. $02 / 2019$.

Quadro 1 - Ano de conclusão do Curso de Pedagogia dos egressos respondentes

\begin{tabular}{|c|c|c|}
\hline Ano & $\mathbf{N = 4 3}$ & Frequência \\
\hline 2012 & 6 & $14,0 \%$ \\
\hline 2013 & 7 & $16,2 \%$ \\
\hline 2014 & 15 & $34,9 \%$ \\
\hline 2015 & 12 & $27,9 \%$ \\
\hline 2016 & 3 & $7,0 \%$ \\
\hline
\end{tabular}

Fonte: Elaboração própria.

No que se refere à formação continuada, em nível de pós-graduação lato sensu, informada pelos egressos, é possível observarmos, de acordo com os dados do quadro 2 , 
Formação e Inserção profissional de egressos de Pedagogia: Estudo de caso em uma IES Confessional fluminnese

que 14 (32,6\%) concluíram; 5 (11,6\%) estão cursando e 24 (55,8\%) ainda não iniciaram. O percentual de concluintes e os que estão cursando a pós-graduação lato sensu denotam a preocupação com a continuidade dos estudos. Embora as pesquisas com cursos de licenciaturas são indicativos de uma profissão social e economicamente desvalorizada, entendemos, assim como Gatti (2010), que

\begin{abstract}
Não há consistência em uma profissionalização sem a constituição de uma base sólida de conhecimentos e formas de ação. Com estas conceituações, estamos saindo do improviso, da ideia do professor missionário, do professor quebra-galho, do professor artesão, ou tutor, do professor meramente técnico, para adentrar a concepção de um profissional que tem condições de confrontar-se com problemas complexos e variados, estando capacitado para construir soluções em sua ação, mobilizando seus recursos cognitivos e afetivos (GATTI, 2010, p. 1360).
\end{abstract}

A função docente, requer uma formação sólida e contínua. Não há lugar para o professor despreparado, que não saiba lidar com problemas que se apresentam no dia a dia das escolas A própria Resolução CNE/CP n ${ }^{\circ}$ 2, de $1^{\circ}$ de julho de 2015 (BRASIL, 2015), como indica Dourado (2015), trata das diretrizes para formação inicial e continuada, demarcando a necessidade de o professor estar em formação contínua ao longo de sua carreira.

A formação em nível de especialização acaba se tornando uma opção imediata para os egressos, por ser muito difundida, ofertada não apenas por universidades, mas por diversas instituições formadoras, por meio de parcerias e, algumas vezes, até pelas próprias empresas ou secretarias de educação, conforme já trazia Gatti (2008).

Quadro 2 - Status dos egressos quanto à formação nos cursos de Pós-graduação lato sensu (Especialização)

\begin{tabular}{|c|c|c|}
\hline Status & $\mathbf{N}=\mathbf{4 3}$ & Frequência \\
\hline Concluído & 14 & $32,6 \%$ \\
\hline Cursando & 5 & $11,6 \%$ \\
\hline Não iniciado & 24 & $55,8 \%$ \\
\hline
\end{tabular}

Fonte: Elaboração própria.

De acordo com o quadro 3, em relação ao Curso de Pós-Graduação stricto sensu, Mestrado, escolhido pelos egressos, observamos que a maioria, 39 (90\%) dos egressos, ainda não possui formação na Pós-Graduação stricto sensu. Apenas $2(5 \%)$ concluíram o Mestrado e 2 (5\%) estão cursando. 
Apesar dos números tímidos, diante dos egressos, é preciso entender qual o perfil dos professores que buscam pós-graduação stricto sensu, uma vez que há muitos mais fatores impeditivos para o acesso a esse tipo de formação. Em primeiro lugar o filtro da seleção, que requer tempo para estudo e preparação de projeto, conhecimento básico de outro idioma. Além disso, após o acesso, é preciso tempo para se cursar as disciplinas, alguns programas requerem, inclusive, dedicação exclusiva, sobretudo a bolsistas.

De acordo com os dados do GEOCAPES, em 2016 o Brasil contava com um total de 266.818 estudantes matriculados em cursos de pós-graduação stricto sensu. Desse total, 126.436 eram estudantes do mestrado acadêmico, 32.742 do mestrado profissional e 107.640 do doutorado acadêmico. Esse número representa um crescimento de aproximadamente $130 \% \mathrm{em}$ relação ao número total de matriculados no ano de 2004, que era de 116.260 estudantes. (JARDIM, 2020, p. 8)

Consideramos que apesar do crescimento das matrículas da pós-graduação stricto sensu, apontado por Jardim (2020), nos últimos anos, se evidencia a redução dos investimentos em educação no pais, com impactos na pós-graduação, sendo visível o corte de bolsas. Conforme explicita Jardim (2020, p. 12): "Entretanto, nos últimos anos, sobretudo a partir de 2015, é possível verificar uma redução na quantidade de bolsistas, nos recursos destinados às bolsas (com exceção da CAPES), e nos orçamentos das duas principais agências de fomento".

Quadro 3 - Status dos egressos quanto à formação nos cursos de Pós-graduação stricto sensu (Mestrado)

\begin{tabular}{|c|c|c|}
\hline Status & $\mathbf{N}=\mathbf{4 3}$ & Frequência \\
\hline Concluído & 2 & $5 \%$ \\
\hline Cursando & 2 & $5 \%$ \\
\hline Não iniciado & 39 & $90 \%$ \\
\hline
\end{tabular}

Fonte: Elaboração própria.

Quadro 4 - Denominação do curso de Pós-Graduação stricto sensu (Mestrado)

\begin{tabular}{|c|c|c|}
\hline Denominação & $\mathbf{N}=\mathbf{4 3}$ & Frequência \\
\hline Educação & 2 & $5 \%$ \\
\hline
\end{tabular}

Fonte: Elaboração própria.

Ainda segundo o autor, tais cortes podem, para além da queda na taxa de crescimento do número de matriculados e titulados/ano na pós-graduação stricto sensu, "significar redução a curto prazo" (JARDIM, 2020, p. 12). Assim, o cenário que já não era convidativo a profissionais da educação tende a se tornar mais complexo e competitivo, havendo inclusive a proposição de induzir uma opção preferencial pelas 
Formação e Inserção profissional de egressos de Pedagogia: Estudo de caso em uma IES Confessional fluminnese

ciências exatas e biomédicas, como anunciado pelo próprio MEC, em detrimento das Humanidades. De acordo com o quadro 4, a Pós-Graduação stricto sensu cursada pelos dois egressos denomina-se Educação. Em relação ao Doutorado, nenhum, egresso iniciou os estudos.

No que se refere à faixa etária dos participantes do estudo, conforme dados apresentados no quadro 5, é possível constatar que $11(25,6 \%)$ encontram-se na faixa etária entre 25-30 anos; 8 (18,5\%) entre 31-35 anos; 7 (16, 3\%) entre 36-40 anos; igualmente $7(16,3 \%)$ entre 41-45 anos; $6(14,0 \%)$ entre 46-50 anos; a faixa etária entre 51-55 anos com $(0 \%)$ e entre 56-60 anos com 4 (9,3\%). Constata-se ainda a preponderância de egressos na idade entre 25-30 anos. A pesquisa de Gatti e Barreto (2009), sobre os cursos de licenciatura, evidencia predominância de faixa etária maior entre os alunos do curso de Pedagogia; apenas 35\% demonstraram estar na idade ideal para o curso.

Quadro 5 - Faixa etária dos egressos participantes do estudo do Curso de Pedagogia

\begin{tabular}{|c|c|c|}
\hline Faixa etária & $\mathbf{N = 4 3}$ & Frequência \\
\hline 25 a 30 & 11 & $25,6 \%$ \\
\hline 31 a 35 & 8 & $18,5 \%$ \\
\hline 36 a 40 & 7 & $16,3 \%$ \\
\hline 41 a 45 & 7 & $16,3 \%$ \\
\hline 46 a 50 & 6 & $14,0 \%$ \\
\hline 51 a 55 & 0 & $0,0 \%$ \\
\hline 56 a 60 & 4 & $9,3 \%$ \\
\hline
\end{tabular}

Fonte: Elaboração própria.

Em relação ao sexo, de acordo com o quadro 6, observamos a preponderância de egressos do sexo feminino, sendo eles um total de 41 (95\%) e apenas $2(5 \%)$ são do sexo masculino.

Quadro 6-Sexo indicado pelos egressos participantes do Curso de Pedagogia

\begin{tabular}{|c|c|c|}
\hline Sexo & $\mathbf{N = 4 3}$ & Frequência \\
\hline Feminino & 41 & $95,3 \%$ \\
\hline Masculino & 2 & $4,7 \%$ \\
\hline
\end{tabular}

Fonte: Fonte: Elaboração própria.

Nóvoa (1988) atribui à denominada feminização do magistério a um fenômeno internacional, fruto das relações econômicas e patriarcais estabelecidas com reflexo na própria forma de conceber o magistério. Neste sentido, Vianna (2013) expressa que, no Brasil, a forte presença de mulheres no magistério do Ensino Primário encontra-se atrelado a um processo iniciado no séc. XIX, com as escolas de improviso, sem vínculo 
estatal. Depois, de forma mais acentuada com a instituição das escolas seriadas após a República e com a extensão progressiva da escola pública.

Desta forma, recorremos ainda a Vianna (2013), para demonstração da forte presença feminina na Educação Básica:

[...]. O forte caráter feminino da docência, na perspectiva da divisão sexual do trabalho, aponta maioria absoluta de mulheres na Educação Infantil, com 97, 9\% de mulheres (97,9\% para creches e 96,1\% para pré-escolas). O Ensino Fundamental ainda indica a presença majoritária de $82,2 \%$ de mulheres, mas aqui com distinções significativas quanto aos anos iniciais $(90,8 \%)$ e finais $(73,5 \%)$. Já o Ensino Médio registra 64,1\% de mulheres e o Ensino Superior conta com $44,8 \%$ de mulheres, incorporadas em diferentes proporções, com alterações importantes da presença feminina tanto na graduação quanto na pós-graduação e também para as áreas disciplinares distintas (BRASIL, MEC/INEP, 2009 apud VIANNA, 2013, p. 166).

Notadamente, os dados oficiais, citados por Vianna (2013) demonstram que na Educação Infantil e nos anos iniciais do Ensino Fundamental a presença feminina no trabalho docente atinge quase a totalidade.

Quadro 7 - Situação dos egressos em relação à inserção profissional

\begin{tabular}{|c|c|c|}
\hline Descrição & $\mathbf{N = 4 3}$ & Frequência \\
\hline Possui atividade remunerada & 37 & $86,0 \%$ \\
\hline $\begin{array}{c}\text { Está desempregado(a) e buscando recolocação } \\
\text { Está desempregado(a) e não pretende voltar ao mercado de } \\
\text { trabalho }\end{array}$ & 5 & $11,6 \%$ \\
\hline
\end{tabular}

Fonte: Elaboração própria.

De acordo com o quadro 7, do total de 43 respondentes, $86 \%$ (37) informaram que possuem atividade remunerada; $11,6 \%$ (5) estão desempregados, buscando recolocação, e 2,4\% (1) estão desempregados e não pretendem voltar ao mercado de trabalho.

As funções desempenhadas pelos $86 \%$ (37) dos egressos que indicaram possuir atividade remunerada são apresentadas no quadro 7. O estudo de Gatti e Barreto (2009), demonstra que, embora haja um consenso entre os pesquisados sobre a desvalorização da profissão, a empregabilidade aparece como um fator distintivo da carreira docente, devido às ofertas de vagas nas redes pública e privada. Ainda assim, as pesquisadoras constatam que a profissão é vista como pouco atrativa, tendo em vista as condições de trabalho e salário do professor. 
Formação e Inserção profissional de egressos de Pedagogia: Estudo de caso em uma IES Confessional fluminnese

Quadro 8 - Relação entre a formação no Curso de Pedagogia e a função desempenhada

\begin{tabular}{|c|c|c|}
\hline Descrição & $\mathbf{N = 3 7}$ & Frequência \\
\hline Está diretamente relacionada à sua formação em Pedagogia & 32 & $86,5 \%$ \\
\hline $\begin{array}{c}\text { Não está diretamente relacionada à sua formação em } \\
\text { Pedagogia, mas gostaria de atuar na área em que se formou }\end{array}$ & 3 & $8,1 \%$ \\
\hline $\begin{array}{c}\text { Não está diretamente relacionada à sua formação em } \\
\text { Pedagogia, por escolha pessoal }\end{array}$ & 2 & $5,4 \%$ \\
\hline
\end{tabular}

Fonte: Elaboração própria.

No que diz respeito à relação entre a formação no curso de Pedagogia e à função que desempenha, o quadro 8 indica que, do conjunto de 37 respondentes, $32(86,5 \%)$ estão em uma função diretamente relacionada à formação em Pedagogia; 3 (8,1\%) não estão atuando em uma função diretamente relacionada à formação inicial. Os demais respondentes $3(8,1 \%)$ atuam em função não diretamente relacionada à formação em Pedagogia, mas gostariam de atuar na área em que se formaram e $2(5,4 \%)$ não estão diretamente relacionadas à formação em Pedagogia por escolha pessoal.

Quadro 9 - Funções dos egressos do Curso de Pedagogia

\begin{tabular}{|c|c|c|}
\hline Função & $\mathbf{N = 4 0}$ & Frequência \\
\hline Professor & 25 & $62,50 \%$ \\
\hline Auxiliar administrativo & 3 & $7,50 \%$ \\
\hline Auxiliar de coordenação & 2 & $5,00 \%$ \\
\hline Auxiliar de creche & 2 & $5,00 \%$ \\
\hline Pedagogo & 1 & $2,50 \%$ \\
\hline Psicopedagogo & 1 & $2,50 \%$ \\
\hline Diretor Pedagógico & 1 & $2,50 \%$ \\
\hline Orientador Educacional & 1 & $2,50 \%$ \\
\hline Tutor EAD & 1 & $2,50 \%$ \\
\hline Chefe de gabinete de vereador & 1 & $2,50 \%$ \\
\hline Técnico na Secretaria Escolar & 1 & $2,50 \%$ \\
\hline Vendedora varejista & 1 & $2,50 \%$ \\
\hline
\end{tabular}

Fonte: Elaboração própria.

No que se refere à função exercida pelos egressos, o quadro 9 apresenta funções que vão desde vendedora varejista a professor, cargos esses que permeiam os diferentes níveis organizacionais, como: operacional, técnico, gestão e docência. Observa-se, ainda, 
predominância na função docente, com 25 egressos exercendo a docência, equivalendo a $(62,50 \%)$.

Ao serem questionados sobre a contribuição do Curso de Pedagogia para o desempenho da profissão que exercem, conforme registrado no quadro 10 , do conjunto de 37 respondentes, $28(75,7 \%)$ avaliam que o Curso contribuiu muito; $7(18,9 \%)$ consideram que contribuiu o suficiente; $2(5,4 \%)$ indicam que contribuiu pouco.

Quadro 10 - Contribuição do curso de Pedagogia para o desempenho na função atual

\begin{tabular}{|c|c|c|}
\hline Descrição & $\mathbf{N}=\mathbf{3 7}$ & Frequência \\
\hline Contribuiu muito & 28 & $75,7 \%$ \\
\hline Contribuiu o suficiente & 7 & $18,9 \%$ \\
\hline Contribuiu pouco & 2 & $5,4 \%$ \\
\hline Não contribuiu & 0 & $0,0 \%$ \\
\hline
\end{tabular}

Fonte: Elaboração própria.

Tal reflexão sobre a contribuição do Curso poderá oportunizar a que o egresso se perceba como professor nas dimensões pessoal e profissional. Com relação a este percurso, Garcia (2009b, p. 127) esclarece:

[...] A inserção profissional no ensino é o período de tempo que abarca os primeiros anos, nos quais os professores hão de realizar a transição de estudantes a docentes. É um período de tensões e aprendizagens intensivas, em contextos geralmente desconhecidos, e durante o qual os professores principiantes devem adquirir conhecimento profissional, além de conseguirem manter um certo equilíbrio pessoal.

Esse processo de inserção profissional compreende, ainda, a forma de os profissionais docentes iniciantes lidarem com o conhecimento, as crenças, os valores de modo a lhes conferir uma identidade profissional.

\section{Avaliação sobre o curso de Pedagogia realizado pelos egressos}

Conforme representado no quadro 11, a concepção dos egressos na avaliação sobre o curso de Pedagogia, do conjunto de 43 respondentes, 29 (67,4\%) avaliaram como ótimo; 9 (20,9\%) consideraram como muito bom; 5 (11,6\%) indicaram como bom.

Quadro 11 - Avaliação do Curso de Pedagogia

\begin{tabular}{|c|c|c|}
\hline Descrição & $\mathbf{N = 4 3}$ & Frequência \\
\hline Ótimo & 29 & $67,4 \%$ \\
\hline
\end{tabular}


Formação e Inserção profissional de egressos de Pedagogia: Estudo de caso em uma IES Confessional fluminnese

\begin{tabular}{|c|c|c|} 
Muito bom & 9 & $20,9 \%$ \\
\hline Bom & 5 & $11,6 \%$ \\
\hline Fraco & 0 & $0 \%$ \\
\hline Ruim & 0 & $0 \%$ \\
\hline
\end{tabular}

Fonte: Elaboração própria.

A qualificação do corpo docente articulada à estrutura oferecida pela instituição e ao comprometimento dos egressos contribui para a qualidade educacional. Partindo desta afirmativa, consideramos a argumentação de Tardif (2018) sobre a necessidade de levar em consideração o que os professores nos dizem a respeito de suas relações sociais com esses grupos, instâncias, organizações etc. Neste sentido, para este autor, no que diz respeito à profissão docente, o conhecimento na realização do trabalho é acompanhado de uma relação social. "[...] os professores não usam o 'saber em si', mas sim saberes produzidos por esse ou por aquele grupo, oriundos dessa ou daquela instituição, incorporados ao trabalho por meio desse ou daquele mecanismo social (formação, currículos, instrumentos de trabalho etc.) (TARDIF, 2018, p. 19, grifo do autor).

Nesse aspecto, os conceitos e justificativas dos egressos sobre o saber profissional estão ligados a uma convergência de saberes provenientes da sociedade, das instituições de ensino, das instituições formadoras etc. Portanto, as instituições formadoras constituem um dos instrumentos de profusão de saberes.

Garcia sustenta que a denominação desenvolvimento profissional se adequa melhor à concepção de professor como profissional do ensino. Por outro lado, declara: “[...] o conceito de 'desenvolvimento' tem uma conotação de evolução e continuidade que, em nosso entender, supera a tradicional justaposição entre formação inicial e formação contínua dos professores" (GARCIA, 2009a, p. 9).

Para este autor, o conceito de desenvolvimento profissional tem se modificado na última década, impulsionado pelos estudos acerca dos processos de ensinar e aprender. Dentre as suas argumentações, para melhor entendimento sobre esse conceito destacamos:

O professor é visto como um prático reflexivo, alguém que é detentor de conhecimento prévio quando acede à profissão e que vai adquirindo mais conhecimentos a partir de uma reflexão acerca da sua experiência. Assim sendo, as atividades de desenvolvimento profissional consistem em ajudar os professores a construírem novas teorias e novas práticas pedagógicas; $\mathrm{O}$ desenvolvimento profissional é concebido como um processo colaborativo, ainda que se assuma que possa existir espaço para 
o trabalho isolado e para a reflexão; Assume-se como um processo que tem lugar em contextos concretos. Ao contrário das práticas tradicionais de formação, que não relacionam as situações de formação com as práticas em sala de aula, as experiências mais eficazes para o desenvolvimento profissional docente são aquelas que se baseiam na escola e que se relacionam com as atividades diárias realizadas pelos professores (GARCIA, 2009a, p. 10-11).

Neste sentido, podemos compreender o desenvolvimento profissional do professor como um modo de ser e assumir formas próprias de refletir sobre seu compromisso pessoal com a questão de ensinar e aprender, demonstrando um profundo conhecimento sobre o conteúdo que ensina, discutindo e buscando formas colaborativas com seus pares a respeito do contexto pedagógico. Portanto, o desenvolvimento profissional comporta todo um arcabouço, envolvendo crenças, valores, assim como a construção do eu profissional, sempre na perspectiva de uma evolução, com vista a "produzir a profissão docente" de que nos fala Nóvoa (1992).

No entanto, as indicações assinaladas, revelando um percentual baixo quando indagados a respeito da contribuição ou não contribuição do Curso, permite a nossa concordância com o argumento de Tardif (2018) sobre a necessidade de se dar continuidade à formação inicial, buscando outros meios:

Tanto em suas bases teóricas quanto em suas consequências práticas, os conhecimentos profissionais são evolutivos e progressivos e necessitam, por conseguinte, de uma formação contínua e continuada. Os profissionais devem, assim, autoformar-se e reciclar-se através de diferentes meios, após seus estudos universitários iniciais. Desse ponto de vista, a formação profissional ocupa, em princípio, uma boa parte da carreira e os conhecimentos profissionais partilham com os conhecimentos científicos e técnicos a propriedade de serem revisáveis, criticáveis e passíveis de aperfeiçoamento (TARDIF, 2018, p. 249).

Neste sentido, a profissionalização pode ser definida na perspectiva de "reformular e renovar os fundamentos epistemológicos do ofício de professor e de educador, assim como da formação para o magistério" (TARDIF, 2018, p. 250). Parece necessária a compreensão de dar continuidade à formação, no sentido requerido pela profissionalização de que nos falam os autores Nóvoa (1988), Garcia (2009a) e Tardif (2018). 
Formação e Inserção profissional de egressos de Pedagogia: Estudo de caso em uma IES Confessional fluminnese

\section{CONSIDERAÇÕES FINAIS}

A pesquisa na área da educação tem suas especificidades, pois trabalha com questões referentes às pessoas ou relacionadas às próprias histórias. Portanto, o resultado obtido difere daquele cujas pesquisas podem ser completamente experimentais com todos os fatores controlados.

De acordo com o que já evidenciamos, neste estudo procedemos a um recorte teórico e analítico, com foco nas dimensões requeridas aos egressos, tendo como referência a concepção de 43 egressos de um curso de Pedagogia e sua interlocução com os referenciais teóricos indicados para subsidiar as análises sobre desenvolvimento pessoal e profissional, tendo em vista o exercício da docência.

Assim, o recorte privilegiado sempre implica opções que nem sempre contemplam a totalidade, seja de um determinado fenômeno, seja dos referenciais creditados. Ao eleger o referencial teórico para a presente pesquisa, temos ciência de que ele é tão somente um olhar e possibilidade dentre tantos outros possíveis e, devido a tantas dimensões requeridas ao licenciado em Pedagogia, certamente outros aportes serão necessários para investigar este profissional.

A pesquisa evidenciou que o curso de Pedagogia teve papel fundamental para a quase totalidade dos egressos que o avaliaram de forma bastante positiva: $67,4 \%$ o consideraram ótimo; $20,9 \%$ o consideraram muito bom e $11,6 \%$ o consideraram bom e apenas dois egressos não afirmam que o curso contribuiu pouco para seu desenvolvimento profissional.

Também, o fato de apenas dois egressos (5,4\%) não estarem inseridos profissionalmente no campo profissional da educação denota que a formação teve desdobramentos para a inserção dos mesmos no campo pretendido. Além disso, o fato de mais de 34,2\% dos egressos já terem iniciado uma pós-graduação, dois deles stricto sensu, mostra que a formação continuada é um valor importante para os egressos, ainda que muitos não tenham tido a oportunidade de dar continuidade aos estudos.

Assim, dentre outras análises, podemos inferir, a partir da generalização do Caso estudado, que o curso de Pedagogia, pensado a partir da formação do professor (FREITAS, 2002; BREZEZINSKY, 2010), possui relevância para o mundo do trabalho e para o desenvolvimento pessoal e profissional dos egressos, uma vez que encontramos recorrências nas respostas em um universo considerável de respondentes. 


\section{Referências}

ANDRÉ, M. Estudo de caso: seu potencial na educação. Caderno de Pesquisa, São Paulo, n. 49, p. 51-54, maio 1984. Disponível em: http://publicacoes.fcc.org.br/ojs/index.php/cp/article/viewFile/1427/1425 Acesso em: 28 out. 2019.

BRASIL. Parecer $n^{\circ}$ 252/1969. Estudos pedagógicos superiores. Mínimos de conteúdos e duração para o curso de graduação em pedagogia. Relator: Valnir Chagas. Documenta, Brasília, n. 100, p. 101-179, 1969.

BRASIL. Constituição da República Federativa do Brasil de 1988. Gov.br. Presidência da República, Brasília, DF, 1988. Disponível em: http://www.planalto.gov.br/ccivil_03/constituicao/constituicao.htm Acesso em: 1 jan. 2019.

BRASIL. Decreto-Lei $n^{\circ} 1.190$, de 4 de abril de 1939. Dá organização à Faculdade Nacional de Filosofia. Câmara dos Deputados, Presidência da República, Brasília, DF, 1939. Disponível em: <https://www2.camara.leg.br/legin/fed/declei/19301939/decreto-lei-1190-4-abril-1939-349241-publicacaooriginal-1-pe.html>. Acesso em: 15 dez. 2019.

BRASIL. Lei no 5.692 de 11 de agosto de 1971. Fixa Diretrizes e Bases para o ensino de $1^{\circ}$ e $2^{\circ}$ graus, e dá outras providências. Diário Oficial [da] República Federativa do Brasil, Brasília, DF, 12 ago. 1971. Disponível em:

<http://www.planalto.gov.br/ccivil_03/leis/L5692impressao.htm>. Acesso em: 10 set. 2019.

BRASIL. Lei $\mathrm{n}^{\circ}$ 9.394, de 20 de dezembro de 1996. Estabelece as diretrizes e bases da educação nacional Gov.br, Presidência da República, Brasília, DF, 1996. Disponível em: <http://www.planalto.gov.br/ccivil_03/LEIS/L9394.htm>. Acesso em: 20 de setembro de 2019.

BRASIL. Resolução CNE/CP $\mathrm{n}^{\circ} 1$, de 15 de maio de 2006. Institui Diretrizes Curriculares Nacionais para o Curso de Graduação em Pedagogia, licenciatura. Portal $M E C$, Ministério da Educação; Conselho Nacional de Educação, Brasília, DF, seção I, p.1-6, 16 de maio de 2006a. Disponível em: <http://portal.mec.gov.br/cne/arquivos/pdf/rcp01_06.pdf> . Acesso em: 12 maio 2019.

BRASIL. Resolução CNE/CP $\mathrm{n}^{\circ}$ 2, de $1^{\circ}$ de julho de 2015. Define as Diretrizes Curriculares Nacionais para a formação inicial em nível superior (cursos de licenciatura, cursos de formação pedagógica para graduados e cursos de segunda licenciatura) e para a formação continuada. Portal MEC, Ministério da Educação; Conselho Nacional de Educação, Brasília, DF, 2015b. Disponível em: <http://portal.mec.gov.br/docman/agosto-2017-pdf/70431-res-cne-cp-002-03072015pdf/file>. Acesso em: 12 maio 2019. 
Formação e Inserção profissional de egressos de Pedagogia: Estudo de caso em uma IES Confessional fluminnese

BRZEZINSKY, I. Normal superior. In: OLIVEIRA, Dalila Andrade; DUARTE, Adriana Maria Cancela; VIEIRA, Livia Maria Fraga. Dicionário: trabalho, profissão e condição docente. Belo Horizonte: UFMG/Faculdade de Educação, 2010, CDROM.

DOURADO, L. F. Diretrizes curriculares nacionais para a formação inicial e continuada dos profissionais do magistério da educação básica: concepções e desafios. Educ. Soc., Campinas, v. 36, n. 131, p. 299-324, Jun. 2015. Disponível em: http://www.scielo.br/scielo.php?pid=S010173302015000200299\&script=sci_arttext. Acesso em: 12 maio 2019.

FREITAS, H. C. L. Formação de professores no Brasil: 10 anos de embate entre projetos de formação. Educ. Soc., Campinas, v. 23, n. 80, p. 136-167, set. 2002. Disponível em: $\quad$ http://www.scielo.br/scielo.php?pid=S010173302002008000009\&script=sci_arttext Acesso em: 12 maio 2019

GADOTTI, M. Perspectivas atuais da educação. São Paulo, Perspectivas, 2000.

GALVÃO, L. M. Constituição, educação e democracia: a Universidade do Distrito Federal (1935-1939) e as transformações da Era Vargas. 238p. Tese (Doutorado em Direito) - Universidade de Brasília, 2017.

GARCIA, C. M. A identidade docente: constantes e desafios. Revista Brasileira de Pesquisa Sobre Formação Docente, Belo Horizonte, v. 1, n. 1, p. 109-131, ago/dez. 2009a.

Disponível em: https://edisciplinas.usp.br/pluginfile.php/4679405/mod_resource/content $/ 1 / 2 . \% 20 \mathrm{Ma}$ rcelo\%2C\%20C.\%20A\%20identidade\%20docente\%20constantes\%20e\%20desafios. \%20\%281\%29.pdf Acesso em: 12 maio 2019.

GARCIA, C. M. Desenvolvimento profissional docente: passado e futuro. Sísifo. Revista de Ciências da Educação, n. 8, p. 7-22, jan./abr. 2009b. Disponível em: https://idus.us.es/bitstream/handle/11441/29247/Desenvolvimento_profissional_doc ente.pdf?sequence=1 Acesso em: 12 maio 2019.

GATTI, B. A. Formação de Professores no Brasil: características e problemas. Educ. Soc, Campinas, v. 31, n. 113, p. 1355-1379, out./dez. 2010. Disponível em: http://www.scielo.br/scielo.php?pid=S0101-73302010000400016\&script=sci_arttext Acesso em: 2 agosto 2019.

GATTI, B. A. Análise das políticas públicas para formação continuada no Brasil, na última década. Rev. Bras. Educ., Rio de Janeiro, v. 13, n. 37, p. 57-70, abr. 2008. Disponível em: http://www.scielo.br/scielo.php?pid=S141324782008000100006\&script=sci_arttext Acesso em: 2 agosto 2019.

GATTI, B. A; BARRETO, E. S. S. Professores do Brasil: impasses e desafios. Brasília, DF: Unesco, 2009.

JARDIM, C. E. A expansão e o financiamento da Pós-Graduação no Brasil e a Meta 14 do Plano Nacional de Educação. FINEDUCA - Revista de Financiamento da 
Educação, v. 10, n. 2, fev. 2020, p. 1-15. Disponível em: https://www.seer.ufrgs.br/fineduca/article/view/87919 Acesso em 20 fev. 2020.

NÓVOA, A. A formação tem de passar por aqui: as histórias de vida no projeto Prosalus. In: NÓVOA, A.; FINGER, M. (Orgs.) O método (auto)biográfico e a formação. Lisboa: Ministério da Saúde. Departamento dos Recursos Humanos da Saúde/Centro de Formação e Aperfeiçoamento Profissional, 1988, p. 107-129.

NÓVOA, A. Formação de professores e profissão docente. In: NÓVOA, A. (Coord.). Os professores e a sua formação. Lisboa: Publicações Dom Quixote, 1992. p. 13-33.

ONU - ORGANIZAÇÃO DAS NAÇÕES UNIDAS. Declaração Universal dos Direitos Humanos, 1948.

UNESCO - ORGANIZAÇÃO DAS NAÇÕES UNIDAS PARA A EDUCAÇÃO, A CIÊNCIA E A CULTURA. Declaração Mundial sobre Educação para Todos: satisfação das necessidades básicas de aprendizagem. Jomtien, 1990.

UNESCO - ORGANIZAÇÃO DAS NAÇÕES UNIDAS PARA A EDUCAÇÃO, A CIÊNCIA E A CULTURA. CONSED, AÇÃO EDUCATIVA. Educação para Todos: o Compromisso de Dakar. Brasília: Unesco, Consed, Ação Educativa, 2001.

UNESCO - ORGANIZAÇÃO DAS NAÇÕES UNIDAS PARA A EDUCAÇÃO, A CIÊNCIA E A CULTURA. Marco de Ação - Educação 2030: Rumo a uma educação de qualidade inclusiva e à educação ao longo da vida para todos. UNESCO, 2015.

OEI - ORGANIZAÇÃO DOS ESTADOS IBERO-AMERICANOS PARA A EDUCAÇÃO, A CIÊNCIA E A CULTURA. A Educação que queremos para a geração dos bicentenários: Metas Educativas 2021, 2008.

OEI - ORGANIZAÇÃO DOS ESTADOS IBERO-AMERICANOS PARA A EDUCAÇÃO, A CIÊNCIA E A CULTURA. A Educação que queremos para a geração dos bicentenários: Metas Educativas 2021. Documento final. Madri, OEI, 2010.

SARLET, I. W. Dignidade da pessoa humana e direitos fundamentais. Porto Alegre: Livraria do Advogado, 2001.

SAVIANI, D. A pedagogia no Brasil: história e teoria. 2 ed. Campinas, SP: Autores Associados, 2012.

SAVIANI, D. Formação de professores: aspectos históricos e teóricos do problema no contexto brasileiro. Revista Brasileira de Educação, Rio de Janeiro, v. 14, n. 40, p. 143-155, jan./abr. 2009. Disponível em: http://www.scielo.br/scielo.php?pid=S1413-24782009000100012\&script=sci_arttext Acesso em: 10 março 2019.

SILVA, C. S. B. Curso de Pedagogia no Brasil: história e identidade. Campinas: Autores Associados, 2003. 
Formação e Inserção profissional de egressos de Pedagogia: Estudo de caso em uma IES Confessional fluminnese

SILVA, C. S. B. Curso de pedagogia no Brasil: uma questão em aberto. In: PIMENTA, S. G. (Org.). Pedagogia e pedagogos: caminhos e perspectivas. São Paulo: Cortez, 2011, p. 131-154.

TANURI, L. M. História da formação de professores. Revista Brasileira de Educação. Rio de Janeiro, n.14, p. 61-88, mai./ago. 2000. Disponível em: http://www.scielo.br/scielo.php?pid=S1413-24782000000200005\&script=sci_arttext Acesso em 10 março 2019.

TARDIF, M. Saberes docentes e formação profissional. Petrópolis, RJ: Vozes, 2018.

VIANNA, C. P. A feminização do magistério na educação básica e os desafios para a prática e a identidade coletiva docente. In: YANNOULAS, S. C. (Org.). Trabalhadoras: análise da feminização das profissões e ocupações. Brasília, DF: Abaré, 2013. p. 159-180.

YIN, R. Estudo de caso: planejamento e métodos. Porto Alegre: Bookman, 2015.

$* * *$

Recebido em: 28 fev. 2021. Aprovado em: 13 jul. 2021.

* Maria de Fátima Barros Pimenta é Doutora em Educação (UCP), professora aposentada da Rede Municipal de Educação de Niterói e professora do curso de Pedagogia do Centro Universitário La Salle do Rio de Janeiro.

E-mail: fatima.pimenta88@gmail.com

** Marcelo Siqueira Maia Vinagre Mocarzel é Doutor em Comunicação (PUC-Rio). Professor do Programa de Pós-graduação em Educação da Universidade Católica de Petrópolis e do Programa de Pós-graduação em Educação da Universidade Estácio de Sá. Professor do Centro Universitário La Salle do Rio de Janeiro.

E-mail: marcelomocarzel@gmail.com

ORCID: http://orcid.org/0000-0002-2780-0054

*** Jardelino Menegat é Doutor em Educação (Unilasalle-Canoas). Professor do Programa de Pós-graduação em Educação da Universidade Católica de Petrópolis. Reitor do Centro Universitário La Salle do Rio de Janeiro .

E-mail: jardelino.menegat@lasalle.org.br

ORCID: http://orcid.org/0000-0003-4003-8882 